\title{
interações \\ IMPACTOS DA TEOLOGIA NO PENSAMENTO DE PAUL RICOEUR
}

\author{
IMPACTS OF THEOLOGY ON PAUL RICOEUR'S THOUGHT
}

\section{René Armand Dentz*}

\begin{abstract}
RESUMO
O intuito desse artigo é mostrar o problema da relação entre filosofia e teologia no pensamento de Paul Ricœur (1913-2005). É possível uma abordagem teológica de um filósofo? Seria razoável que Ricœur abordasse temas como o mal, o perdão e a reconciliação? Trata-se, como veremos a seguir, de uma relação complexa no próprio pensamento de nosso filósofo. Por isso, apresentaremos o desenvolvimento da relação entre a filosofia e a teologia em algumas de suas obras, utilizando, para tanto, seus principais comentadores da temática em questão. E possível afirmar que alguns aspectos tornam o projeto filosófico ricoeuriano singular: há um cuidadoso diálogo com diversos pensadores de diferentes épocas e campos do conhecimento. Ricœur parece absorver as grandes contribuições teológicas e de áreas afins do século XX. O diálogo entre o filosófico e o teológico, nesse aspecto, alarga o campo de pensamento da filosofia, enriquecendo-o, protegendo-o de pré-compreensões. Palavras-chave: Limite. Hermenêutica. Revelação. Crítica. Convicção.
\end{abstract}

\begin{abstract}
Georgia, tamanho 11, negrito. Inglês)
The purpose of this article is to show the problem of the relationship between philosophy and theology in the thought of Paul Ricœur (1913-2005). Is a philosophical theological approach possible? Would it be reasonable for it to address issues such as evil, forgiveness and reconciliation? It is, as we shall see below, a complex relationship in our philosopher's own thinking. Therefore, we will present the development of the relationship between philosophy and theology in some of his works, using his main commentators on the subject in question. It is possible to affirm that some aspects make the Ricour 's philosophical project unique: there is a careful dialogue with different thinkers from different times and fields of knowledge. Ricour seems to absorb the great theological and related contributions of the 2oth century. The dialogue between the philosophical and the theological, in this aspect, broadens the field of thought of philosophy, enriching it, protecting it from pre-understandings.
\end{abstract}

Keywords: Border. Hermeneutics. Revelation. Criticism. Conviction.

\section{INTRODUÇÃO}

É possível de antemão afirmar que podemos elucidar o pensamento ricoeuriano a partir de inspirações teológicas. Talvez seja mesmo mais prudente afirmar que estabeleceremos um diálogo com temáticas teológicas. O próprio Ricœur sempre recusou a

\footnotetext{
* Doutor em teologia pela FAJE. Pós-Doutor em Educação pela Warsaw University. Pós-Doutorando em Teologia pela PUC-Rio. Pós-Doutorando em Teologia pela Université de Fribourg (Suisse). Professor universitário e Psicanalista. Brasil. ORCID: 0000-0002-4842-0827. E- mail: dentz@hotmail.com
} 
etiqueta de filósofo cristão, procurando manter equidistantes a sua confissão de fé e o procedimento filosófico. Dessa maneira, o grande fundamento da reflexão ricoeuriana é a filosofia, embora a teologia, sobretudo através de seus estudos de exegese bíblica, também ocupe um respeitável lugar em suas pesquisas. Alguns temas são limítrofes entre os dois saberes, notadamente: o mal, a esperança e o perdão. Este último é visto por ele como uma síntese entre a história, a memória e o esquecimento. No entanto, além disso, também não pode ser pensado sem o mal e a esperança. Ou seja, apesar de nosso autor não ter elaborado uma vertente teológica de seus estudos sobre o perdão (talvez não tenha elaborado explicitamente, mas essa vertente está presente de maneira indireta em obras como Amour et Justice e Penser la Bible (RICOEUR, 1998), como o fez em relação ao mal e à esperança, não é possível estudar a temática sem levar em consideração sua inspiração e sua abordagem teológica.

\section{COMO RICOEUR SE ENCONTRA COM A TEOLOGIA?}

O pensamento teológico concebido por Ricœur é compreendido, de forma inaugural, pela nomeação de Deus; e a palavra dita pelo homem em resposta, considera a filosofia e não ousa traspassar limites, como, por exemplo, indagando o que é Deus?. Filosofia e teologia dividem, segundo ele, um mesmo destino diante da retirada do nome de Deus; elas não podem surgir senão por um excesso de discurso, um discurso de segundo grau. O tema da esperança, por exemplo, passa a ser, dessa forma, uma via aberta onde o saber parou em sua desmedida, tanto filosófica quanto teológica, o que explicaremos em breve. E não importa se a teologia é mais afirmativa, dogmática e, finalmente, mais do que toda filosofia, sendo considerada como parceira do diálogo. Eis um ponto de abertura do diálogo entre a filosofia e a religião:

Como entrar neste círculo, digo que foi uma oportunidade transformada em destino por uma escolha contínua. Uma oportunidade, porque se poderia sempre dizer que, se eu tivesse nascido noutro lugar as coisas não teriam, evidentemente, seguido o mesmo curso. Mas, este argumento nunca me impressionou muito, porque me imaginar nascido noutro contexto é me imaginar não ser mais eu (RICOEUR, 1995a, p. 219-220).

Na obra La Critique et la Conviction (1995a), Ricœur afirma que uma filosofia não pode ser pensada sem ser concebida em si mesma. O mito da transparência do Iluminismo é denunciado e a leitura dos mestres da suspeita é decisiva tanto para os filósofos iluministas quanto para a religião. Crítica e convicção perpassam um caminho único na formação de um 
pensamento, muitas vezes por meio de um limiar muito tênue. No entanto, no prefácio de Soi-même comme un autre, Ricœur (1990) demonstra que a crítica deve ser autônoma, não entrando no campo religioso, o que podemos dizer ser uma tendência mais próxima a um agnosticismo, o que retoma nos últimos anos de sua trajetória intelectual, sobretudo na obra póstuma Vivant jusqu'à la mort (RICOEUR, 2007). Sobre tal obra, é importante aqui elucidar alguns pontos, pois a consideramos central, visto que é uma obra de caráter enfaticamente pessoal, o que é característica do nosso pensador: refletir sobre sua historicidade.

A meditação sobre a morte acaba por resultar numa hesitação entre dois polos. $\mathrm{O}$ primeiro caracteriza-se "pela necessidade e dificuldade de fazer o luto de um querer-existir depois da morte" (RICOEUR, 2007, p. 33). O segundo, pela boa disposição, juntamente com a graça esperada de existir vivente até à morte. $\mathrm{O}$ cuidado de existir vivente até à morte reporta-se à vivência pessoal do filósofo, a qual ficou marcada pela doença degenerativa da sua esposa. A meditação sobre a morte pressupõe a necessidade e a dificuldade de fazer o luto. Efetivamente, nota-se em Ricœur uma oscilação interna a propósito da aceitação da morte. Esse trabalho de luto incide sobre a tarefa mínima da reflexão filosófica: a clarificação conceptual que, quando reflete sobre o estatuto dos mortos, assume um valor terapêutico. O esforço ricœuriano dedica-se a exorcizar a interrogação sobre o que será dos mortos e sobre o seu investimento afetivo. O questionamento filosófico é então exercitado a propósito da antecipação interiorizada da morte em si mesma como agonia antecipada.

Ricœur introduz, em primeiro lugar, a distinção entre o agonizante e o moribundo para se livrar da antecipação interiorizada. É a partir do testemunho de Lucie Hacpille, médica de cuidados paliativos, que essa distinção se opera. De acordo com a médica, os doentes prestes a morrer não têm a percepção de si mesmos enquanto "moribundos" (HACPILLE apud RICOEUR, 2007, p. 42), isto é, como quem vai morrer daí a pouco, mas, antes, como ainda vivos, ainda que mais não estejam que a alguns minutos do seu falecimento. Para o agonizante, ainda estar vivo significa a emergência da mobilização dos recursos mais profundos da vida, que lhe permitem ainda se afirmar. Ela é, por assim dizer, o Essencial na trama do tempo da agonia. Esse Essencial que é, em certo sentido, o religioso, ou o religioso em comum, o qual transgride as limitações consubstanciais ao religioso confessional e confessado no limiar da morte. Por outras palavras, esse momento de mobilização é um momento de graça interior. Na entrevista que dá em La critique et la conviction (RICOEUR, 1995a) esse momento é, aliás, designado como sendo o fundamental. Ele remete para a aparição da “coragem de estar vivo até à morte” (RICOEUR, 2007, p. 48) 
quando a vida se escreve, face à morte, com um V maiúsculo. Contudo, pensar esse momento e a sua força, é também correr o risco de resvalar para a literatura sobre as experiências místicas: por isso mesmo, é preciso saber simultaneamente dar mostras de alguma desconfiança, enquanto se acolhe a graça interior de um determinado morrer.

Em se tratando do pensamento teológico propriamente dito, uma das obras mais significativas de nosso autor é Penser la Bible (RICOEUR, 1998), bem como as abordagens sobre parábolas, a nomeação de Deus, a relação entre Amor e Justiça. Mesmo se Ricœur utiliza diferentes tipos de leitura das Escrituras, ele demarca claramente um número de evidências da leitura histórica. Desse modo, a teologia cristã não seria uma fonte, mas já o resultado do encontro da filosofia e do pensamento bíblico: A atitude crítica será mais do lado filosófico, o momento religioso não sendo, enquanto tal, um momento crítico; é o momento de adesão a uma palavra reputada superior a mim, e isto, na leitura querigmática, confessional (RICOEUR, 1995a, p. 219).

Sendo assim, o trabalho reflexivo sobre o cristianismo é constituído por duas tarefas, segundo Ricœur: a hermenêutica dos textos bíblicos, e a teologia fundamental. As duas fundamentam a atitude de suspeita da filosofia. Boyd Blundell (2014) afirma:

\begin{abstract}
A hermenêutica reorganiza o conceito metafísico da verdade, afastando-se de noções de correspondência ou coerência na direção da sua revelação e manifestação. Ela também concebe a história com uma seriedade sem precedentes na filosofia, e é caracterizada por sua concentração nos textos. A hermenêutica de Tracy vem principalmente de Ricour, seu amigo e colega na Universidade de Chicago. E embora a apropriação teológica da hermenêutica de Tracy seja cheia de dificuldade, é um projeto importante. (BLUNDELL, 2014, p. 128).
\end{abstract}

Neste contexto, é importante a ideia de que a esperança assenta naquilo que vai ser intitulado, em outro momento, como afirmação originária, ou seja, primazia ontológica do ser sobre o nada ou da afirmação sobre a negação. Todavia, a função da esperança é apenas de impacto, não podendo ter nenhum papel substantivo na reflexão filosófica porque, para Ricœur, Filosofia e Religião são discursos irredutíveis um ao outro e, por isso mesmo, devem manter as suas diferenças epistemológicas claras.

Depois de sua obra Le Conflit des Interprétations, de 1969 (RICOEUR, 1969) (não desconsiderando outras, mas nela, sobretudo, por causa de suas abordagens hermenêuticas), Ricœur torna-se um nome de referência para a teologia, sobretudo sobre os temas da Graça e do ser humano. Segundo Amherdt (2004), a Comissão Bíblica Pontifícia refere-se a ele como autor de grande método, ao lado de Bultmann e Gadamer: 
A linguagem religiosa da Bíblia é uma linguagem simbólica que "dá a pensar" (o trabalho do texto), uma linguagem em que não se cessa de descobrir riquezas de sentido (em sua polifonia inesgotável), uma linguagem que visa uma realidade transcendente (seu referente específico, a nominação de Deus) e que ao mesmo tempo desperta a pessoa humana à dimensão profunda de seu ser, a suas potencialidades mais próprias e ao testemunho da esperança (AMHERDT, 2004, p. 57).

Por outro lado, foi apontada ausência de referências pneumatológicas. Para a Comissão, o filósofo francês traça um caminho racional, mesmo que aberto à transcendência. Podemos afirmar que a fé bíblica é uma fonte motivadora da reflexão de nosso filósofo, mesmo não se colocando como fundamento. A religião se mostra como uma inspiração, como uma fonte não filosófica da filosofia:

O filósofo pode contribuir para discernir a pluralidade dos registros que atravessam o corpus bíblico. É a isso que se dedicou toda a hermenêutica bíblica de Ricœur: restituir a polifonia que o conduz a refletir até as fronteiras mais distantes do continente filosófico com o gênero profético, que é objeto de sua última Gifford Lectures (DOSSE, 2008, p. 568).

A trajetória filosófica de Ricœur é um esforço para inserir na reflexão todos os aspectos que possam contribuir para a compreensão mais ampla do complexo ser humano, em conflito consigo mesmo, com a existência, bem como com a transcendência:

Amor, para mim, por exemplo, não pertence à ética; ele pertence à poética da vontade. E eu concordo com o argumento de Jean Greisch, precisamente porque ele mesmo é um teólogo e um filósofo da razão. Ele faz o mesmo, e Lévinas, também, em seus livros filosóficos não tem argumentos do Talmud. Ele escreve seus estudos talmúdicos separadamente (RICOEUR apud REAGAN, 1996, p. 120).

Boyd Blundell (2014, p. 175) critica essas concepções, que com frequência enfatizam demasiadamente as entrevistas e as obras religiosas do filósofo francês. Ele explora, ao contrário, uma fronteira entre a filosofia e a teologia, abrangendo um amplo conjunto de obras de Ricœur. Segundo esse autor, podem-se distinguir três fases em Ricœur: a da hermenêutica bíblica, a da filosofia da religião, e a da filosofia pura; e sugere que as duas primeiras receberam ênfase excessiva na recepção de Ricœur nos Estados Unidos, que o fazem mais teológico do que realmente é. Blundell examina os trabalhos sobre a narrativa e $o$ eu, e emprega a estrutura padrão de Ricœur, ida e volta.

Desde o início, Ricœur considerou a racionalidade filosófica como um desafio a assumir na condição de crente. Dessa forma, procura no círculo hermenêutico compreender mais, para crer; e crer mais, para compreender e alcançar um caminho de maior harmonia entre a filosofia e a religião, mas nunca uma solução simplista. "Eu sempre caminhei sobre 
duas pernas. Não foi apenas por precaução metodológica que não misturei os gêneros, mas porque procuro afirmar uma dupla referência, absolutamente primeira para mim” (RICOEUR, 1995a, p. 211).

Tanto nas intervenções filosóficas, quanto em seus trabalhos exegéticos, Ricœur se esforça para rejeitar tudo aquilo que poderia ser identificado como um fundamentalismo redutor, seja especulativo, conceitual ou teológico. É justamente o diálogo entre a filosofia e a religião que ele vê como um antídoto para tal problema. Esse diálogo não pode se instituir sem essa alteridade principal, sem essa diferenciação bem clara entre dois campos, que animam, com o mesmo rigor, um pensamento que nunca perde como horizonte a incompletude. Essa cisão entre os dois domínios teve mesmo uma tendência a se reforçar. Os artigos publicados por Ricœur nos anos cinquenta e sessenta justapõem as intervenções dos dois registros. Por outro lado, os três volumes de Lectures (RICOEUR, 1994) separam esses domínios. Em Lectures 2 se dedica aos filósofos, em Lectures 3 se situa na fronteira da filosofia, estudando temas teológicos.

Em Soi-même comme un autre, Ricœur (1990) não quis, mesmo que seu editor, François Wahl, não visse nenhuma objeção, que sua hermenêutica do si, propriamente filosófica, se finalizasse com dois capítulos de hermenêutica bíblica. Ele se explica no prefácio da obra, reconhecendo que sua escolha é discutível e pode ser criticada, mas mantém um discurso filosófico autônomo. Fica aqui, claro, que ele pretende evitar críticas no campo teológico de que seria um cripto-filósofo, pois tentaria transformar a fé bíblica em uma filosofia; e no campo filosófico, de que seria um cripto-teólogo, pois traria à discussão temas que não são próprios à razão filosófica. Por certo, em ambientes onde a crítica filosófica é mais acirrada, como na França, Ricœur parece não se sentir à vontade para abordar temas teológicos. No entanto, ministra várias conferências pela Europa, por exemplo, as Gifford Lectures, ${ }^{1}$ em Edimburgo, nas quais também aborda temas com forte inspiração teológica. Essa forma de ascese perpassa toda sua obra, configurando-o como um "tipo de filósofo [em] que a nomeação efetiva de Deus está ausente e onde a questão de Deus, na condição de uma questão filosófica, permanece em um suspense que podemos dizer agnóstico.” (RICOEUR, 1990, p. 36).

Essa preocupação da distinção conduziu a um tratamento à parte de Ricœur no cenário fenomenológico francês, como nos apresenta Dominique Janicaud (1991). Em um ensaio ousado, no qual critica vários fenomenólogos que fizeram uma passagem sem cuidado para a teologia (como Lévinas, Jean-Luc Marion, Michel Henry e Jean-Louis

${ }^{1}$ Ver The Gifford Lectures (TEMPLETON PRESS, 2020). 
Chrétien), preserva Ricœur: "Ricœur teve o cuidado de suavizar o passo. Suas estruturas metodológicas lhe conduziram a multiplicar as precauções hermenêuticas prévias a toda passagem da fenomenologia à teologia” (JANICAUD, 1992, p. 13). O respeito ao espírito husserliano em Ricœur é saudado como apropriação de um programa fenomenológico que se limita à aparência das coisas, às suas manifestações.

Do lado religioso, a preocupação de desmitologizar e de marcar as aporias e os limites da especulação filosófica conduz a entrever o horizonte de uma dupla separação em direção ao poético (da pura especulação filosófica e teológica), que é o que procura, em última instância, Ricœur:

[...] eventos em minha vida pessoal e o espetáculo do mundo me deram sensibilidade para o fato de que há sofrimento injustificado espalhado pelo mundo. Há uma linguagem a ser encontrada. É o problema de Auschwitz, o problema da memória e do perdão. Estou interessado em explorar as áreas de interseção entre o religioso, o poético, o ético e o histórico (RICOEUR apud REAGAN, 1996, p. 135).

Essa posição de fronteira fará de Ricœur um pensador muito influente e fecundo para a teologia fundamental, sobretudo pelas questões referentes à revelação, ao testemunho, ao nome de Deus. Sua abordagem dos símbolos permite aos teólogos pensarem a teologia de forma holística.

Se Ricœur não se interessa em transcender a diferença entre protestantes e católicos em um ecumenismo institucional, também não podemos esquecer o fato de seu vínculo com muitos teólogos católicos: "Eu me sinto em casa quando estou com os jesuítas do Centre Sèvres e dos meus amigos do Institut Catholique de Paris: eles têm os mesmos problemas que eu, problemas do sentido e do não sentido" (RICOEUR, 1995a, p. 251). Outro fato significativo é a dupla evolução dos católicos desde o Concílio Vaticano II, e dos protestantes, em sua passagem de uma teologia inspirada em Barth, para uma teologia inspirada em Bultmann. Ambas favoreceram uma mudança em direção a uma abertura hermenêutica da teologia.

\section{TEÓLOGOS NA FILOSOFIA RICOEURIANA}

O primeiro grande teólogo que influenciou Ricœur foi, sem dúvida, Karl Barth, no momento em que nosso autor, pela primeira vez, abordou uma temática limítrofe entre a filosofia e a teologia. Em outro momento de similar perspectiva, Ricœur sofre influência do, também suíço, Pierre Thévenaz, filósofo protestante que procura, do mesmo modo, 
delimitar a filosofia e a teologia, buscando uma ideia de uma filosofia sem absoluto. Abordaremos os dois sequencialmente.

Após a primeira guerra, o prestígio de Karl Barth, teólogo suíço da Basileia, alcançou seu apogeu. Barth rompe radicalmente com o protestantismo liberal e toma distância de uma ideia de acesso direto a Deus pela intuição. Segundo a teologia liberal, é preciso partir do homem, e seguir através de um trabalho histórico-crítico sobre os textos fundadores para entender de forma mais profunda o Evangelho.

A influência de Barth em Ricœur é tão profunda que, mesmo quando Ricœur entra posteriormente em nova fase de pensamento - a da desmitologização -, influenciado por Rudolf Bultmann, as marcas deixadas pelas propostas do teólogo suíço permanecem. Primeiro, podemos verificá-las na postura de escuta sobre a qual insiste Barth e que define o gesto filosófico de Ricœur: o filósofo cristão é aquele que escuta a Palavra como os outros fiéis e quer colocá-la em prática sobre o terreno dos humanismos. A segunda definitiva apropriação do barthismo é a centralidade relacionada à Palavra, que reenvia ao Evento e afasta o pensamento de um fechamento em sistema, de toda totalização prematura.

Segundo Olivier Abel (1996), Karl Barth e Husserl ocupam em Ricœur o mesmo lugar em seu percurso, exercendo um papel de verdade fundamental e aporia radical: "Eu colocaria sobre o mesmo lugar a Graça em Barth e a historicidade em Husserl” (ABEL, 1996, p. 33). A afirmação de uma doação primeira, à qual o homem não tem acesso, como uma Graça que não podemos nos dar, remeteria ao mundo-da-vida (noção central para o entendimento do termo historicidade), anterior a todo modo de vida, a toda atividade cultural:

Embora a formação inicial de Ricœur à filosofia - nos anos de liceu -, tenha sido de cariz predominantemente neotomista, não há dúvida que o estudo de Kant marcou tão profundamente a sua personalidade que ele chegou a aplicar-se a si próprio a apelação de "neo-kantiano pós-hegeliano". Isso não impede que a tese da impossibilidade filosófica do acesso à realidade de uma criação divina tenha encontrado em Ricœur um terreno já balizado pela compreensão da fé cristã segundo Calvino e Karl Barth (RENAUD, 2012, 158159).

A valorização da Palavra como revelação, leva Barth a uma cristologia. É por Cristo que Deus leva ao homem sua humanidade. A religião verdadeira, segundo Barth (1957), passa por uma crítica severa da religião para reencontrar seu caminho na fé. Esse caminho é aquele da Cruz de Jesus Cristo na condição de realidade tangível da revelação. Ele segue uma cristologia consequente, uma concentração cristológica. Barth, desse modo, exclui qualquer tipo de teologia natural. A única via é aquela da revelação realizada no Cristo 
encarnado, crucificado e ressuscitado. Ricœur retoma essa cristologia como seu horizonte: a unidade final da Escritura chama recapitulação em Cristo, significando que a unidade ainda não se realizou, mas existe como promessa:

O Deus da Epístola aos Romanos é o Deus absconditus, o totalmente Outro, conceito que Barth extrai de Rudolf Otto, inserindo-o, porém, não em um contexto fenomenológico, e sim teológico. Nenhum caminho vai do homem a Deus: nem a via da experiência religiosa (Schleiermacher), nem a da história (Troeltsch), e tampouco uma via metafísica; o único caminho praticável vai de Deus ao homem e se chama Jesus Cristo (GIBELLINI, 2002, p. 21).

De acordo com o teólogo suíço, é imprescindível efetivar uma revolução copernicana na relação entre o homem e Deus. Não é o homem que está no centro, mas Deus. É o que parece ser um caminho feito por Ricœur, pois em todas as suas abordagens antropológicas, procura não se limitar a um antropocentrismo e sim evidenciar a figura da relação, de pólos. Isso pode ser percebido em sua eidética, sua empírica e sua poética da vontade. Essa mudança é resultado de uma tentativa de retomar a ênfase na divisão que os mestres da Reforma, Lutero e Calvino, haviam realizado: entre fé e religião, entre imanência e transcendência. Com sua Dogmática, Barth restabelece as certezas da crença, convidando a uma postura modesta, a uma humildade necessária, convencido de que é impossível ao homem falar completamente de Deus. As questões teológicas agora passam a estar centradas nesse limite. A finitude do homem e o pecado constituem uma distância intransponível com um Deus que pode se revelar a ele, mas como verdade escondida. Dessa forma, Deus se revela se escondendo e se esconde revelando-se.

O apoio filosófico de Kant e a compreensão teológica da fé na esteira de Karl Barth reforçaram-se reciprocamente para suscitar em Ricœur, cristão da Igreja Reformada da França, a intuição e a convicção de que o único acesso filosófico à questão de Deus tem que passar pela análise filosófica dos textos bíblicos e pela interpretação dos seus símbolos (RENAUD, 2012, p. 159).

Ricœur, como a maior parte dos protestantes de sua época, foi marcado pelas teses de Barth no pós-guerra, como afirmamos anteriormente. A militância, por meio de um cristianismo social que nosso filósofo realizou, é ilustradora desse fato. Definindo o modo de intervenção do cristianismo na política, Ricœur assume o movimento do engajamento barthiano e da ruptura entre as duas ordens do mundo: de um lado, a fé cristã implica uma inserção no mundo e um projeto político. De outro, não existe, entre a fé cristã e uma política determinada, um lugar necessário, mas certo hiato. A descontinuidade, sobre a qual insiste Barth, entre Deus e a sociedade humana, é fonte de trabalho e esperança. Ricœur retoma 
essa perspectiva ainda que conceba as relações entre o profetismo e a filosofia. Ele recusa toda forma de confusão entre esses dois registros, sempre preocupado em distingui-los.

Outra contribuição do pensamento de Barth a Ricœur foi a sustentação antropológica (acentuadamente protestante) do teólogo suíço de que "[...] o nada, é que o Cristo venceu, se aniquilando a si mesmo na Cruz.” (RICOEUR, 1998, p. 44) (dito por Ricœur, mas referindo-se a Barth) e a partir da vitória do Cristo a humanidade pode conhecer o nada. Aqui achamos que o termo utilizado pelo teólogo suíço indica mais do que o nada, indica também o fútil, o vão que permeia a própria existência humana. O que falta a partir da vitória do Cristo para Barth é o próprio fim do mal. E, neste sentido, Ricœur se filia, ainda mais, à tradição protestante, implicando que, para o fim do mal acontecer, há a necessidade de consolidar instituições justas, tema abordado anos mais tarde em Soi-même comme un autre (RICOEUR, 1990) e Le Juste (RICOEUR, 1995b). Ricœur insiste que estranhamente há uma coordenação sem conciliação entre a mão direita e a mão esquerda de Deus (temática de forte inspiração barthiana):

O nada também vem de Deus, mas em outro sentido, diferente da origem da criação boa, que é, para Deus, a eleger no sentido da eleição bíblica, e a rejeitar algo que, por ser rejeitado, existe sob o modo do que quer que seja. Este lado de rejeição é de alguma forma "a mão esquerda" de Deus. "Nada é o que Deus quer. Ele só existe porque Deus não o quer." (RICOEUR, 1998, p. 45).

Esta passagem esclarece o pensamento de Barth na visão de Ricœur. O mal existe na medida em que é o negado por Deus, mas é capaz de ser assumido pelo homem em sua falibilidade, talvez até mesmo em negação à própria vontade de Deus. O mal é a escolha pelo que é rejeitado. E mais, o mal radical é respondido, uma vez que é parte da criação como o que é rejeitado pelo próprio Deus, senhor desse nada:

No período da Dogmática, vão tomando consistência as seguintes afirmações centrais: a) Deus é Deus, mas é Deus para o mundo: ao Deus que é o totalmente Outro sucede a figura de Deus que se faz próximo ao mundo; b) o mundo é mundo, mas é um mundo amado por Deus: passa-se do conceito da infinita diferença qualitativa aos conceitos de aliança, reconciliação, redenção, como conceitos-chave do discurso teológico; c) Deus encontra o mundo em sua Palavra, em Jesus Cristo: daí se segue a concentração cristológica subsequente ao enfoque escatológico do período dialético (GIBELLINI, 2002, p. 30).

Ricœur (1969) afirma as duas interpretações possíveis à abordagem de Barth sobre o mal. Como dissemos, de um lado, inserindo-o na teodiceia. Isto se a bondade de Deus predomina contra o mal desde o momento da criação, como nos mostra o Gênesis; Ricœur afirma a esse propósito que a potência de Deus ficaria restrita em Barth pela própria 
existência “dual do mal” (RICOEUR, 1969, p. 76). Dessa maneira, o aforismo da teodiceia se concretiza: Deus é todo poderoso, mas o mal existe. Para Ricoeur (1969), se interpretamos Barth por esse viés, verificamos apenas um compromisso efêmero. Contudo, por outro lado, podemos interpretar Barth na medida em que recusa a "lógica de não-contradição" (RICOEUR, 1969, p. 77) e a totalização sistemática da teodiceia, na medida em que o mal é a efetividade da mão esquerda de Deus, e essa paradoxalmente aceita pelo homem que sofre em face do mal.

A interpretação de nosso filósofo dos estágios do entendimento sobre o mal de acordo com a filosofia e a teologia contribui ao seu próprio especular filosófico. Estes estágios esclarecem como Ricœur se insere na tradição e como é inovadora a sua abordagem da questão do mal, não mais de maneira a ignorar o sofrimento do homem, ainda que de um só homem. O mal agora é visto de maneira personalista; não se trata mais do problema do mal em sua essência, mas como este se dá no mundo. Dessa forma, se distancia das interpretações pregressas, mas de onde obtém subsídios para sua avaliação. Lembramos que Ricœur designa sua filosofia como filosofia da ação, fundamentando o homem em situação. O mal se torna então um problema não mais em sua relação com a bondade da criação, mas já em relação ao homem, que especula sobre o mal, sobre o homem que perpetra o mal e com o homem que sofre o mal. Dessa forma, sua resposta sobre a origem do mal, diverso da resposta sobre o mal radical na teodiceia, se dá no campo da história. Em La Symbolique du mal (RICOEUR, 1960, v. 2), o mal é visto em perspectiva da experiência humana.

Por outro lado, a proposta estabelecida por Ricœur escapa em parte à distinção fundamental afirmada por Karl Barth entre filosofia e teologia, sobretudo do recorte feito pelo teólogo suíço entre razão humana e razão divina. Ao contrário, Ricœur anuncia uma intenção filosófica por meio de um roteiro teológico. A filosofia pode compreender, por exemplo, o mal, mas deve partir dos símbolos, das narrativas, pelos quais a consciência religiosa pode se compreender. Mesmo que a intenção desses símbolos e dessas narrativas seja confessional, o filósofo não pode se confundir com esse fato. Ele deve, por outro lado, buscar uma ingenuidade segunda (ou seja, depois de fazer uma crítica inicial, sem perder o encantamento do imaginário religioso). Os grandes símbolos permitem trazer à consciência os elementos que os fundamentam. No entanto, essa compreensão não é estritamente religiosa:

Quer dizer que poderíamos retornar à primeira ingenuidade? Não é assim. De todo modo, alguma coisa está perdida, irremediavelmente perdida: o imediatismo da crença. Mas se não podemos mais viver segundo a crença originária, as grandes simbólicas do sagrado, 
podemos, nós modernos, na e pela crítica, tender a uma segunda ingenuidade (RICOEUR, 1960, 326).

Ricœur encontra, mais tarde, um filósofo protestante seguidor de Barth, o também suíço, Pierre Thévenaz. Este defende um tipo particular de relação mais viva entre a filosofia e a fé. Ele recusa a alternativa, com frequência proposta no protestantismo, entre a rejeição do logos em nome da Sola Fide e uma atitude que consiste em procurar harmonizar, como faz a teologia liberal, uma filosofia vagamente espiritualista e uma fé sem confissão de fé. Essa posição de humildade é claramente uma atitude tributária da influência barthiana. Dessa forma, a filosofia está diante de Deus, jamais em confronto. Ricœur situa a característica protestante da filosofia de Thévenaz em sua primazia de valor da Cruz de Cristo, que é também muito barthiana: a Cruz de Cristo, evento puro, tocou essa inteligência lhe enunciando a morte do deus filosófico, o fim também de uma teologia filosófica, tornando o caminho livre para uma filosofia sem absoluto (THÉVENAZ, 1960).

Em Thévenaz (1960), na via da busca de uma filosofia protestante a filosofia sem absoluto não é uma filosofia ateia ou anticristã. Ela consiste, antes, no encontro entre a razão filosófica e a experiência-choque do anúncio cristão. Nessa experiência-choque, a sabedoria humana é qualificada como sendo a da loucura perante Deus. E com isso inaugura-se uma reflexão filosófica que põe o homem a descoberto. Essa reflexão leva à conversão filosófica da razão absoluta, ligada a Deus, na razão humana perante Deus. A razão desabsolutizada e destotalizada, saindo do seu autismo, é autônoma em relação a Deus, uma vez que a meditação da experiência cristã mais não é que humana. Ela tem a ver com a experiência cristã que torna possível a autonomia da filosofia. A filosofia sem absoluto é, portanto, a filosofia fora do autismo de uma razão humana perante Deus.

Através desse tema thévenaziano, a atitude agnóstica de Ricœur foi formulada no artigo Un philosophe protestant: Pierre Thévenaz (RICOEUR, 1957). Ricœur toma de Thévenaz a ideia de uma filosofia responsável perante Deus. É com a responsabilidade da inteligência que o filósofo deve responder, de acordo com uma polaridade de apelo e resposta, através do próprio ato filosófico.

Mas nesse mesmo artigo, que foi um prefácio a Thévenaz, Ricœur observa e interroga: “O crente confessa a sua responsabilidade de filósofo perante Deus; mas será que o filósofo sabe que está perante Deus?” (RICOEUR, 1957, p. 51). Em seguida, avança que “a questão que a filosofia de Pierre Thévenaz nos coloca é a de saber se uma filosofia protestante é somente uma filosofia redutora, iconoclasta” (RICOEUR, 1957, p. 53). A noção de limite e a de conversão ao para cá (l'en deçà) são assim formuladas por Ricœur. Ele conhecia bem a 
fraqueza argumentativa de Thévenaz, e que estava ligada à radicalidade do perante Deus que ele colocava. Essa fraqueza era a de saber em que medida o perante Deus ainda faz parte da reflexão filosófica. E também a questão de como o filósofo sabe estar perante Deus. Com Ricœur, podemos perguntar-nos se "a conversão do divino à humanidade pode colocar a mesma dúvida se o 'perante Deus' não pertence à reflexão enquanto tal" (RICOEUR, 1957, p. 53). Assim, o traço agnóstico ricœuriano encontra-se formulado pelas suas questões sobre o perante Deus de Thévenaz.

Essa preocupação, a qual perseguiu Ricœur durante muito tempo, reaparece tardiamente com um eco thévenaziano, no Fragmento o (1), um dos últimos escritos de Ricœur, publicado em Vivant jusqu'à la mort (RICOEUR, 2007).

Se a problematização inserida no princípio protestante for pertinente a ambos os campos, como se configuram nos nossos dias, à teologia e à filosofia, teremos um interessante resultado: de que, justamente, é a partir do cristianismo nascente que, na história ocidental, dá-se uma problematização que, em um primeiro momento, contesta tanto o próprio fazer teológico - que tem se nutrido do fazer filosófico ocidental, e o nutrido também -, assim como a certas pretensões do fazer filosófico. Em um segundo momento, esta problematização especificamente cristã é que possibilita tanto à teologia quanto à filosofia libertarem-se de si mesmas, de suas próprias limitações e pretensões de palavra última; ou seja, de certo modo, podem ser pós-modernas. Nesse sentido, chegamos ao resultado de que é a partir de uma inspiração religiosa, que tanto a teologia, quanto a filosofia, podem se livrar, para serem elas mesmas na assunção de sua plena humanidade. Para isso, teremos que falar do conceito de novo a partir das pretensões de verdade que o cristianismo propôs diante do mundo do seu tempo e que aqui apresentamos como uma verdadeira subversão dos modos de compreensão clássicos dominantes, uma subversão da própria linguagem:

Esse momento que acabamos de nos surpreender, esse momento da mudança, onde a transcendência platônica reenvia a inteligência e a linguagem do lado do humano e remete o homem ao seu lugar, é fundamental na reflexão de Pierre Thévenaz: o abandono da supertranscendência de Plotino, englobada na própria inversão do movimento que ela provocou, é o próprio momento de destruição da teologia onde temos visto imediatamente o impacto de uma fé protestante na filosofia (RICOEUR, 1992, p. 252).

Nesse sentido, Thévenaz consegue captar bem esta nuance que se destaca do movimento protestante, que, para ele, toma a forma de um princípio heurístico, que inspira a sua própria filosofia e que o ajuda a elaborar uma proposta de colocação do problema férazão de modo original e instigante. A singularidade do filósofo suíço e um de seus impactos 
no pensamento de Ricœur consistem em assumir, francamente como positivo - e assim como fruto da inserção do cristianismo na história do pensamento -, aquele processo de secularização que se deplorou e se deplora.

\section{CONSIDERAÇÕES FINAIS}

Como podemos verificar ao longo do artigo, a proposta de Ricœur em pensar a partir de, ou em diálogo com, temas teológicos, se dá de formas diversas. Adotamos o critério de análise a partir de influências ou inspirações (ou simplesmente impactos) em temas centrais de sua filosofia. É possível verificar momentos na obra de Ricœur que se relacionam a uma influência ou a um projeto teológico, mesmo que de forma indireta. Dentre essas influências estão presentes: exegetas, teólogos e filósofos da religião. Além disso, procuramos demonstrar o caminho hermenêutico traçado por Ricœur em direção a uma hermenêutica bíblica e sua preocupação em delimitar as singularidades da linguagem religiosa.

Por tudo o que vimos nesse artigo, é possível concluir que alguns aspectos tornam o projeto filosófico ricoeuriano singular: há um cuidadoso diálogo com diversos pensadores de diferentes épocas e campos do conhecimento. Ricœur parece absorver as grandes contribuições teológicas e de áreas afins do século XX. O diálogo entre o filosófico e o teológico, nesse aspecto, alarga o campo de pensamento da filosofia, enriquecendo-o, protegendo-o de pré-compreensões.

Ricœur aborda temas importantes em seu pensamento como um todo a partir de diálogos ou mesmo inspirações iniciais (ou permanentes) teológicas. Mesmo não propondo elaborar propriamente uma teologia, as discussões do referido campo são fundamentais ao seu horizonte filosófico. Dessa maneira, afirmamos que o filósofo francês alarga seu campo intelectual, realizando, de fato, uma filosofia do diálogo. Para os dias atuais, sem dúvida sua trajetória deixa um enorme legado e uma potencialidade hermenêutica, sobretudo se pensamos nos enormes desafios apresentados pela pós-modernidade.

\section{REFERÊNCIAS}

ABEL, Olivier. Paul Ricoeur: la promesse et la règle. Paris: Michalon, 1996.

AMHERDT, François-Xavier. L'herméneutique philosophique de Paul Ricoeur et son importance pour l'exégèse biblique. Paris: Les Éditions du Cerf, 2004.

BARTH, Karl. Church Dogmatics. Edinburgh: Clark, 1957. 
BLUNDELL, Boyd. Paul Ricoeur between theology and philosophy: detour and return. Bloomington: Indiana University Press, 2014.

DOSSE, François. Paul Ricoeur: les sens d'une vie. 3. ed. Paris: La Découverte, 2008. GIBELlini, Rosino. A Teologia do Século XX. São Paulo: Loyola, 2002.

JANICAUD, Dominique. Le tournant théologique de la phénoménologie. Paris: Éclat, 1992.

REAGAN, Charles. Paul Ricoeur: his life and his work. Chicago: Chicago University Press, 1996.

RENAUD, Michel. A interpretação da criação segundo Paul Ricoeur. Lisboa: Universidade Católica Portuguesa, 2012.

RICOEUR, Paul. Un philosophe protestant: Pierre Thévenaz. Paris: Esprit, 1957.

RICOEUR, Paul. Finitude et culpabilité, v.1 (l'homme faillible); v.2 (la symbolique du mal). Paris: Aubier, 1960.

RICOEUR, Paul. Le conflit des interprétations: essais d'herméneutique I. Paris: Editions du Seuil, 1969.

RICOEUR, Paul. Soi-même comme un autre. Paris: Seuil, 1990.

RICOEUR, Paul. La Vie chrétienne. Journal de l’Église presbytérienne au Canada, n. 41, 4-6, 1992.

RICOEUR, Paul. Lectures 3: Aux fronteires de la philosophie. Paris: Seuil, 1994.

RICOEUR, Paul. La critique et la conviction. Paris: Calmann-Lévy, 1995a.

RICOEUR, Paul. Le juste. Paris: Esprit, 1995b.

RICOEUR, Paul. Penser la Bible. Paris: Seuil, 1998.

RICOEUR, Paul. Vivant jusqu’à la mort: suivi de fragments. Paris: Seuil, 2007.

TEMPLETON PRESS. The Gifford Lectures: over 100 years of lectures on natural theology. Disponível em: https://www.giffordlectures.org/. Acesso em: 21 set. 2020.

THÉVENAZ, Pierre. La condition de la raison philosophique. Neuchâtel: Éditions de la Baconnière, 1960. 